\title{
Domain Structure of Magnetic Nanocrystalline Materials Studied by Electron Holography
}

D. Shindo

Institute of Multidisciplinary Research for Advanced Materials, Tohoku University, Sendai 9808577, Japan

Recently, various advanced magnetic materials have been developed by fabricating fine grains in nanometer scale. Fe-based alloys $\mathrm{Fe}_{73.5} \mathrm{Cu}_{1} \mathrm{Nb}_{3} \mathrm{Si}_{13.5} \mathrm{~B}_{9}$ prepared by rapid quenching and annealing at appropriate temperatures show good properties for soft magnets [1]. It was reported that the magnetic properties drastically changed with the change of the annealing temperature or the change of the microstructure $[2,3]$. In order to understand the magnetic properties of these materials, it is important to investigate not only the microstructure but also the magnetic domain structure. In this paper, by using the electron holography method, the magnetization distribution of $\mathrm{Fe}_{73.5} \mathrm{Cu}_{1} \mathrm{Nb}_{3} \mathrm{Si}_{13.5} \mathrm{~B}_{9}$ is investigated. Electron holography experiment was carried out with a JEM$3000 \mathrm{~F}$ transmission electron microscope installed with a field emission gun and a biprism. The magnetic field around the specimen was reduced to $0.2 \mathrm{mT}$ by switching off and then degaussing the objective lens.

Figures 1 (a) and 1 (b) show the coercive force $\left(\mathrm{H}_{\mathrm{c}}\right)$ and the permeability $\left(\square_{\mathrm{r}}\right)$ of $\mathrm{Fe}_{73.5} \mathrm{Cu}_{1} \mathrm{Nb}_{3} \mathrm{Si}_{13.5} \mathrm{~B}_{9}$ with various heat treatments. The lowest coercive force is obtained at the annealing temperature of $823 \mathrm{~K}$. It is also noted that the permeability takes large values at this temperature. Figure 2 (a) - (d) show TEM images of $\mathrm{Fe}_{73.5} \mathrm{Cu}_{1} \mathrm{Nb}_{3} \mathrm{Si}_{13.5} \mathrm{~B}_{9}$ with various heat treatments. While an as-quenched specimen (Fig. 2(a)) is amorphous state, fine grains of about $10 \mathrm{~nm}$ and enlarged grains of $50 \AA^{`} 200$ $\mathrm{nm}$ are observed in Figs. 2 (b) and 2 (d), respectively. Figure 3 (a) - (c) show the reconstructed phase images of $\mathrm{Fe}_{73.5} \mathrm{Cu}_{1} \mathrm{Nb}_{3} \mathrm{Si}_{13.5} \mathrm{~B}_{9}$ films with the increase of tilting angle. In the top of Fig. 3 (a) of the as-quenched specimen with no tilt, monotonous closure domains are clearly seen. It is noted that the magnetic lines of force are parallel to the specimen edges, thereby eliminating the surface magnetic charge. It is interesting to note that the shape of the closure domain starts to change at the magnetic field of $8.3 \mathrm{~A} / \mathrm{m}$ which well corresponds to the coercive force of the bulk specimen of $6.9 \mathrm{~A} / \mathrm{m}$ (Fig. 1 (a)). On the other hand, it is seen that the magnetic domain of the specimen annealed at $823 \mathrm{~K}$ is more sensitive to the magnetic field as seen in Fig. 3 (b), well corresponding to low coercivity and high permeability. In the case of the specimen annealed at $973 \mathrm{~K}$, the size of magnetic domains becomes smaller, and the magnetic lines of force deviate significantly from the monotonous line shape. The irregularity in the shape of the magnetic lines of force is considered to result from the inhomogeneous magnetization distribution due to the bcc Fe and the Fe-B compounds. Being different from Figs. 3(a) and 3 (b), the magnetic lines of force do not change so much for the tilt. The difference directly indicates the strong pinning of magnetic domain walls due to the precipitates, resulting in the drastic increase of the coercive force and the decrease of the permeability [4].

\section{References}

[1] Y. Yoshizawa et al., J. Appl. Phys. 64 (1988) 6044.

[2] G. Herzer, IEEE Trans. Magn. 25 (1989) 3327.

[3] R. Schäfer et al., J. Appl. Phys. 69 (1991) 5325.

[4] The author wishes to thank Dr. Y. Yoshizawa and Mr. Y.-G. Park for providing the specimens and for the cooperation. 


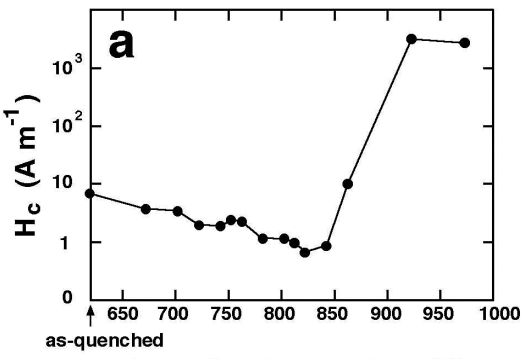

Annealing temperature $(\mathrm{K})$

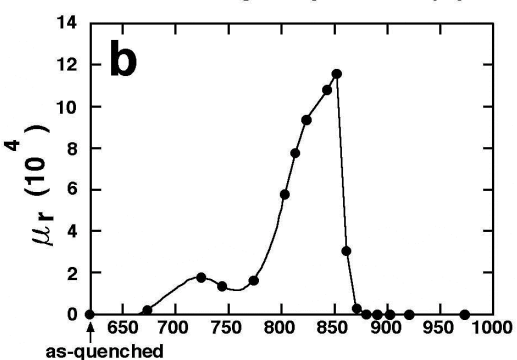

Annealing temperature (K)

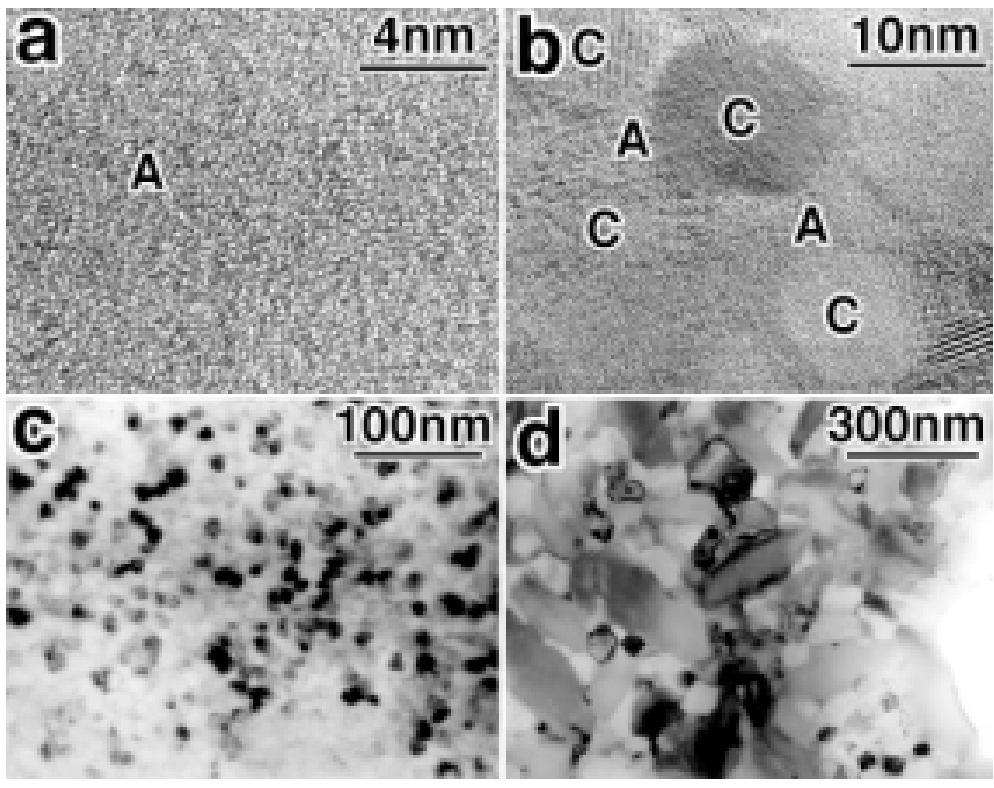

Fig. 2. TEM images of $\mathrm{Fe}_{73.5} \mathrm{Cu}_{1} \mathrm{Nb}_{3} \mathrm{Si}_{13.5} \mathrm{~B}_{9}$ asquenched (a), annealed at $823 \mathrm{~K}$ (b), $923 \mathrm{~K}$ (c) and $973 \mathrm{~K}(\mathrm{~d})$.
Fig. 1. Coercive force (a), permeability (b) of $\mathrm{Fe}_{73.5} \mathrm{Cu}_{1} \mathrm{Nb}_{3} \mathrm{Si}_{13.5} \mathrm{~B}_{9}$ as a function of annealing temperature.
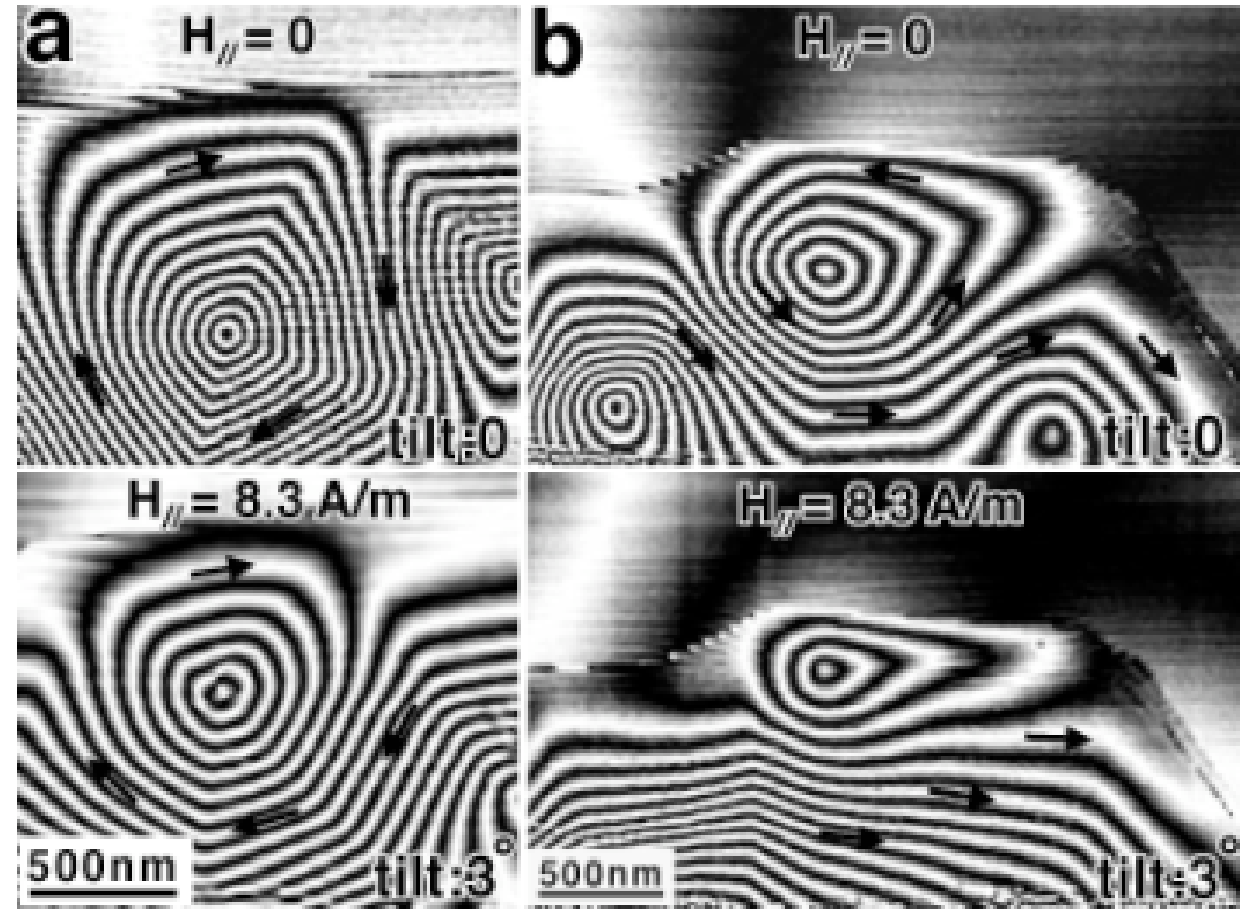
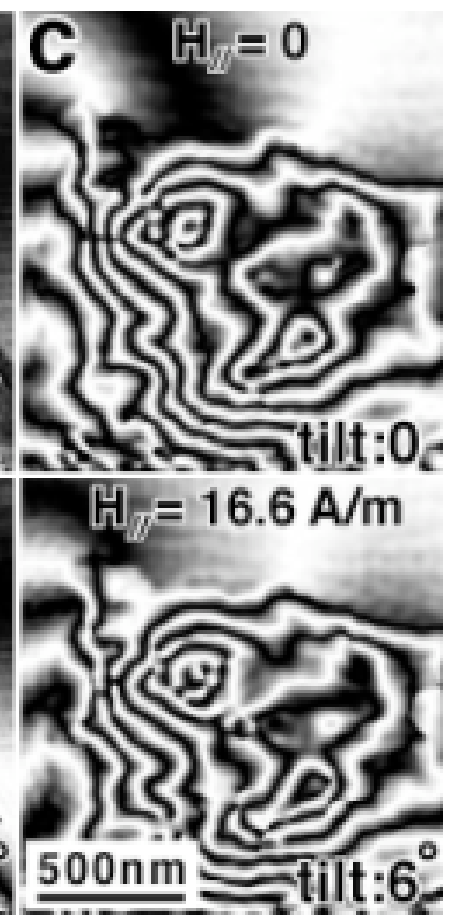

Fig. 3. Reconstructed phase images of $\mathrm{Fe}_{73.5} \mathrm{Cu}_{1} \mathrm{Nb}_{3} \mathrm{Si}_{13.5} \mathrm{~B}_{9}$ as-quenched (a), annealed at $823 \mathrm{~K}$ (b), and $973 \mathrm{~K} \mathrm{(d)} \mathrm{with} \mathrm{the} \mathrm{increase} \mathrm{of} \mathrm{tilting} \mathrm{angle.} \mathrm{The} \mathrm{direction} \mathrm{of} \mathrm{the} \mathrm{magnetic} \mathrm{lines} \mathrm{of} \mathrm{force} \mathrm{is}$ indicated by arrows. $\mathrm{H}_{/ /}$indicates the magnetic field in the film plane due to the tilt. 